P1-12

\title{
BASIC EXPERIMENT FOR A FASTENING DEVICE FOR THE VERTICAL OUTER WALLS OF HIGH-RISE BUILDINGS
}

\author{
Young-Bog Ham ${ }^{1}$, Byung-Ju Lim ${ }^{1}$, Chang-Dae Park ${ }^{1}$, Dae-Myoung Kim ${ }^{1}$, \\ Bok-Kyu Kim ${ }^{2}$, and Se-Hyeong Jeon ${ }^{3}$ \\ ${ }^{I}$ Department of Energy Systems, Korea Institute of Machinery \& Materials, Daejeon, Korea \\ ${ }^{2}$ Department of R\&D Center, Poonglim Co., Ltd, Seoul, Korea \\ ${ }^{3}$ Innotems Innovation Systems Co., Daejeon, Korea \\ *Corresponding author(bzoo77@kimm.re.kr)
}

\begin{abstract}
In order to perform maintenance on the outer walls of a high-rise building, including sweeping, painting and repairs, a device that enables the easy attachment/detachment of working equipment such as a gondola to the outer wall of a building is necessary. Though vacuum suction pads can be used to fasten equipment to a vertical wall easily and without causing damage to the contact surface, their suction force should be designed by considering both external conditions and the loads of working equipment.

In this study, we performed a basic experiment on the vacuum suction force of suction pads attached to a vertical wall under various load conditions.
\end{abstract}

Keywords: Vacuum Suction Force, Suction Pads, High-rise Building, Vertical Outer Wall, Fastening Equipment

\section{INTRODUCTION}

Gondola systems are widely used in the construction and maintenenace servicing of the outer walls of high-rise buildings. A gondola is moved up and down the outer walls, with the winder installed on the building's roof. Conventionally, workers work on a gondola platform, which is moved up and down a wall when carrying out sweeping, painting or repair works. However, as modern buildings are often more than 30 stories high, the risks of such work have increased while the work efficiency has decreased, leading to the need for robot systems designed for maintenance work on outer walls. Gondola-type building work robots have a larger working area since a wire winch system can be installed on a building's roof. A winch can be installed easily without needing to alter a building's outer wall structure. However, it is difficult for workers using gondola systems suspended by wires to carry out precision works such as painting as gondolas tend to sway around in the wind. Even in an environment without an external load, the gondola platform has to be fixed onto a wall to perform such works as sweeping or painting. Indeed, the platform has to be fixed against vertical and horizontal loads on the outer wall. Since the fixing must not damage a wall requiring such work, vacuum suction pads are used as fixing devices.

Guido La Rosa et al. developed a low-cost, lightweight robot system which can travel in a vertical direction using 8 suction cups[1]. The NINJYA BIPED developed by Nishi al Miyazaki can travel along a wall's surface using small suction cups[2-4]. Hwang Kim et al. developed a robot system which can travel along vertical walls stably and continuously, using endless tracks attached with vacuum pads[5].

The vacuum suction pads developed in preceding studies for movment and work on vertical walls are lightweight, making them easy to use in various applications. However, for systems where additional heavy loads are applied, such as a gondola, the performance of the vacuum pads has to be investigated precisely. 
In this study, an item of testing equipment was fabricated to measure the vacuum pressure and attachment force of a vacuum suction pad according to changes in compressed air pressure. In addition, the attachment forces were measured by varying the rate of the external load applied to the vacuum pad.

\section{ATTACHMENT THEORY}

A vacuum means an empty space from which air and other gases are absent or have been removed to a certain degree. A perfect vacuum, in which there is absolutely nothing in a given space, is impossible. Generally, a vacuum is the state of a space in which the gas pressure is lower than that of the atmosphere. Vacuum systems can be classified by the range of absolute vacuum pressure, as presented in Table 1. Most vacuum suction movement devices belong to the low vacuum range.

$$
W=(P \times A) \div 760
$$

Where, $\mathrm{W}$ is th suction force[kgf], $\mathrm{P}$ is the relative vacuum pressure[-mmHg], and $\mathrm{A}$ is the cross-sectional vacuum area of $\operatorname{pad}\left[\mathrm{cm}^{2}\right]$. Equation (1) expresses the relationship between the relative vacuum pressure and the attachment force of the vacuum pad, which is proportional to the relative vacuum pressure in the pad and the crosssection of the pad. To select a vacuum suction pad, the required suction force must be calculated using following Equation (2).

$$
F=m \times(g+a)
$$

Where, $\mathrm{F}$ is the calculated suction force[kgf], $m$ is mass $[\mathrm{kg}], g$ is the gravitational acceleration $\left[\mathrm{m} / \mathrm{s}^{2}\right]$, and $a$ is environmental acceleration $\left[\mathrm{m} / \mathrm{s}^{2}\right]$. Here, the environmental acceleration is caused by an unforeseen condition such as emergency stop. The suction force calculated with Equation (2) concerns a smooth surface; thus, a safety ratio of 2 or higher should be applied in unfavorable work environments.
Table 1. Classification of vacuum pressure

\begin{tabular}{c|c}
\hline Classification & Pressure Range(Torr) \\
\hline \hline Low vacuum & $760 \sim 1$ \\
\hline Medium vacuum & $1 \sim 10^{-3}$ \\
\hline High vacuum & $10^{-3} \sim 10^{-7}$ \\
\hline Extra high vacuum & $10^{-7}>$ \\
\hline
\end{tabular}

\section{EXPERIMENT}

\subsection{SCHEMATICS OF TEST EQUIPMENT}

Fig. 1 shows a schematics diagram of the suction pad test apparatus fabricated for this study. The apparatus was designed to enable the insertion of a building's outer wall sample into a frame. It also was designed to allow the testing of wall samples of various surface configurations.

Two pneumatic cylinders were used to apply the horizontal and vertical loads to the vacuum pad, and load cells were installed to measure the loads between the cylinder and pad. A sliding block was installed at the crosspoint of two axes to apply the horizontal and vertical loads simultaneously. The vacuum suction pad was fixed onto the sliding block, which is moved by the cylinder. Fig. 2 shows the fabricated test equipment.

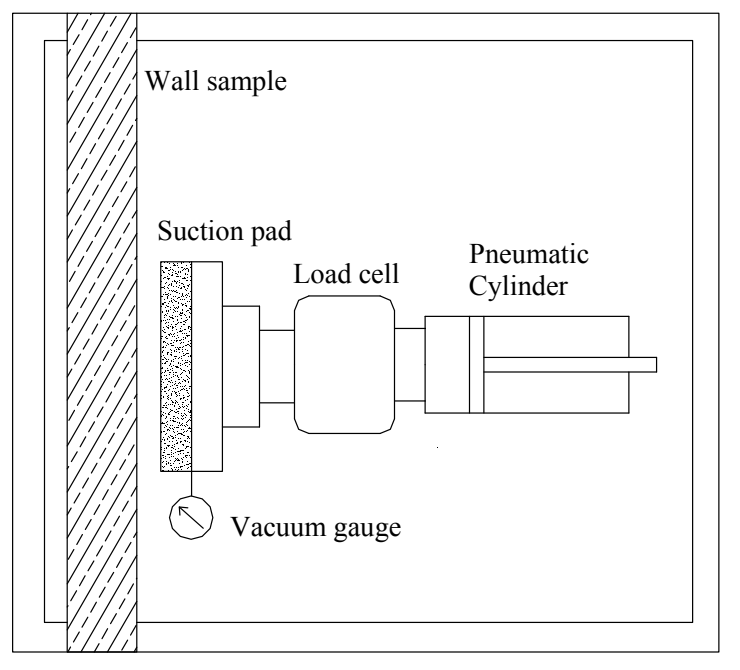

Fig. 1 Schematic diagram of the suction pad test device 


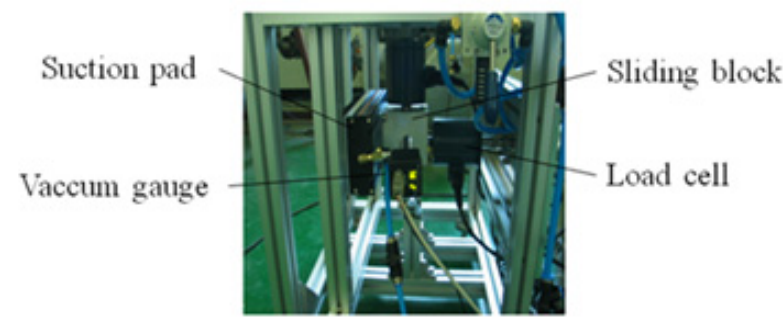

Fig. 2 Test equipment of suction pad

\subsection{COMPONENTS OF TEST EQUIPMEMNT}

\section{1) Tested Suction Pad}

The suction pad used in the experiment was a VG Series of VMECA, as shown in Fig. 3. The suction pad is based on an ejector, which removes the air in the pad using the kinetic energy of compressed air.

Ejectors are used to suck up and discharge, transfer or mix gases, liquids or powders. Unlike pump systems, they have no moving parts and their simple structure enables trouble-free operation.

Table 2 presents the specifications of the suction pad provided by the manufacturer. The dimensions of the suction pad are $300 \mathrm{~mm} \times 130 \mathrm{~mm}$. The suction pad is made of flexible sealing foam, with multiple holes measuring $12 \mathrm{~mm}$ in diameter and $20 \mathrm{~mm}$ in depth.

The suction pad can be attached to the irregular surfaces of vertical walls. A digital pressure gauge was installed on the side of the suction pad to measure and record the vacuum pressure in the test.

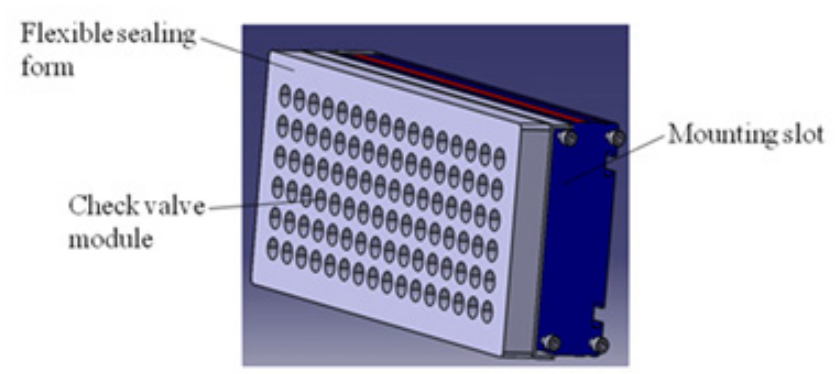

Fig. 3 3D schematic diagram of the vacuum pad

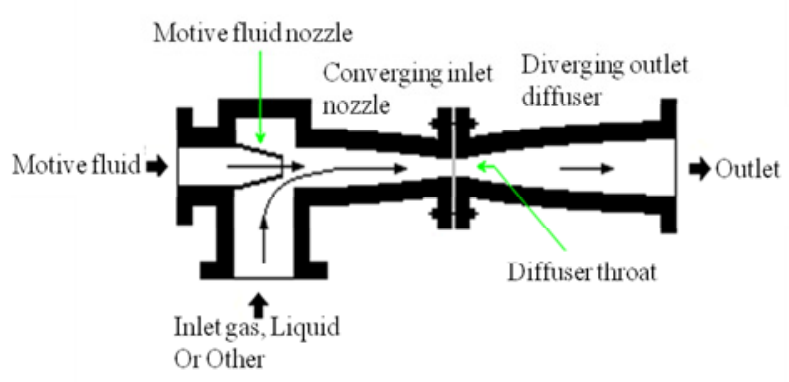

Fig. 4 Ejector principle for vacuum pad

Table 2. Specifications of the sub-components

\begin{tabular}{c|c}
\hline Contents & Specifications \\
\hline Max. vacuum pressure & 200 Torr \\
\hline Max. supply flowrate & $1,448 \mathrm{~N} \ell / \mathrm{min}$ \\
\hline Supply air pressure & $0.4 \sim 0.7 \mathrm{MPa}$ \\
\hline Working fluid & Dry compressed air \\
\hline Air consumption & $416 \mathrm{~N} \ell / \mathrm{min}$ \\
\hline Pad area & $390 \mathrm{~cm}^{2}$ \\
\hline Noise level & $55 \sim 65 \mathrm{dBA}$ \\
\hline
\end{tabular}

2) Sub-components of the test equipment

The building's outer wall sample was prepared as a flat surface-type. The load cell can measure up to $200 \mathrm{~N}$ of tensile and compressive forces. The pneumatic cylinder can move bi-directionally using compressed air fed through a switch valve. The pressure of the compressed air from a 1 $\mathrm{MPa}$ compressor was controlled by a pressure regulator to obtain the desired pressure. The measurement data were collected and saved using a DAQ from National Instrument.

To convert the measurement signals from the load cell, an SCXI-1314 terminal was applied to an SCXI-152, which is a strain measurement module. The environmental variables were monitored and stored at intervals of $0.1 \mathrm{~s}$ using LabVIEW software.

Table 3 presents the specifications of the subcomponents of the test equipment. 
P1-12

Table 3. Specifications of the sub-components

\begin{tabular}{c|l}
\hline Contents & \multicolumn{1}{|c}{ Specifications } \\
\hline Wall type & Shape: flat surface \\
\hline Load cell & Range: max. $200 \mathrm{~N}$ \\
\hline Vacuum gage & $\begin{array}{l}\text {-Range: } 10^{-3} \sim 10^{3} \text { Torr } \\
\text {-Accuracy: } 0.1 \% \text { of indicated } \\
\text { decade }\end{array}$ \\
\hline Pneumatic cylinder & Max pressure : $1 \mathrm{MPa}$ \\
\hline Compressor & Supply pressure : $1 \mathrm{MPa}$ \\
\hline DAQ & Model: NI SCXI 1520(8 ch $)$ \\
\hline
\end{tabular}

\section{EXPERIMENT RESULTS}

The suction performance test was conducted according to the following procedures:

a. Set the air pressure with the pressure regulator.

b. Move the suction pad on surface the concrete wall sample using the vertical cylinder.

c. Attach the suction pad on the sample by ejecting the compressed air.

d. Apply a force perpendicular to the wall to the suction pad by injecting compressed air into the cylinder.

e. Increase the cylinder force until the suction pad falls off the wall.

Firstly, to determine the maximum suction performance of the suction pad, the attachment force was measured by varying the pressure of the compressed air between 4 to 6 bars. Fig. 4 shows the graphic depiction of the attachment force according to changes in compressed air pressure.

Table 4 presents the vacuum pressure in the pad and the attachment force at the respective air pressure.

The relative vacuum pressure of the suction pad was found to be between $350 \sim 540 \mathrm{mmHg}$. At this time, the maximum attachment force was between $179 \sim 277 \mathrm{~N}$.

Fig. 5 shows the graph of the attachment forces at the cylinder load rates of $20 \mathrm{~N} / \mathrm{sec}, 40 \mathrm{~N} / \mathrm{sec}$, and $70 \mathrm{~N} / \mathrm{sec}$ at the constant air supply pressure of $0.5 \mathrm{MPa}$. Table 5 presents the vacuum pressures and maximum attachment forces at the load rates.

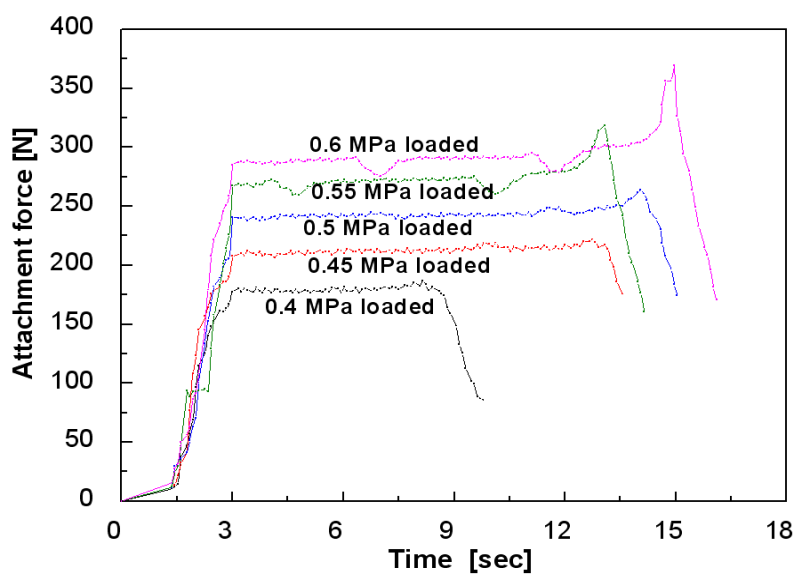

Fig. 5 Results graph of attachment force with air pressure

Table. 4 Result data of air pressure

\begin{tabular}{|c|c|c|c|}
\hline $\begin{array}{c}\text { Supply } \\
\text { pressure } \\
\text { (MPa) }\end{array}$ & \multicolumn{2}{|c|}{ Vacuum presure } & $\begin{array}{c}\text { Max. } \\
\text { attachment } \\
\text { force } \\
\text { (N) }\end{array}$ \\
\hline 0.4 & 410 & 350 & 179 \\
\hline 0.45 & 383 & 377 & 193 \\
\hline 0.5 & 274 & 486 & 249 \\
\hline 0.55 & 260 & 500 & 256 \\
\hline 0.6 & 220 & 540 & 277 \\
\hline
\end{tabular}

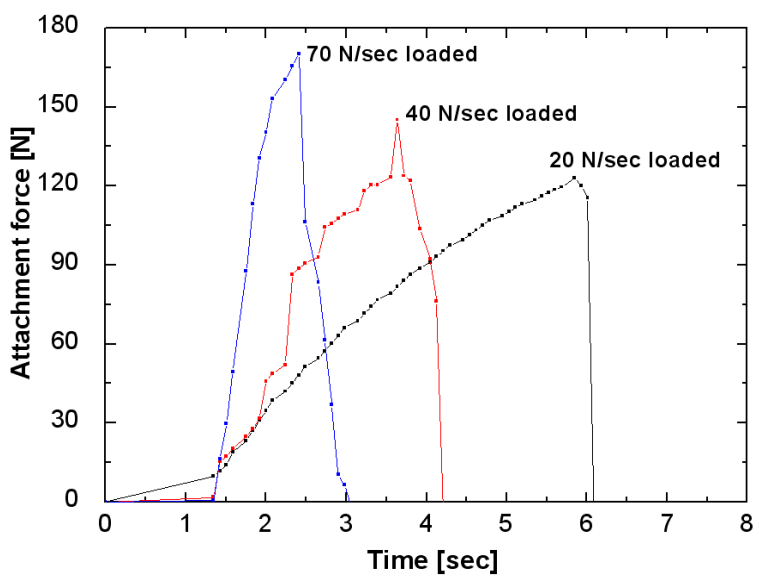

Fig. 6 Results graph of attachment time 
Table. 5 Results data with load veloclry

\begin{tabular}{|c|c|c|}
\hline $\begin{array}{c}\text { Load Rate } \\
(\mathbf{N} / \mathbf{s})\end{array}$ & $\begin{array}{c}\text { Vacuum } \\
\text { presure } \\
(-\mathbf{m m H g})\end{array}$ & $\begin{array}{c}\text { Max. attachment } \\
\text { force } \\
\mathbf{( N )}\end{array}$ \\
\hline 20 & 429 & 123 \\
\hline 40 & 477 & 145 \\
\hline 70 & 520 & 170 \\
\hline
\end{tabular}

\section{CONCLUSIONS}

In this study, a vacuum suction pad testing equipment was fabricated to measure the attachment force of the pad.

The testing equipment was designed to allow insertion of the concrete wall sample and to measure both the vertical and horizontal attachment forces using a slide block. The attachment force of an ejector-type vacuum suction pad in a perpendicular direction to the wall's surface was tested. It was found that the higher the compressed air pressure, the higher the vacuum pressure in the suction pad and, proportionally, the maximum attachment force of the suction pad. The rate of increase of the air pressure in the cylinder was varied, which in turn led to variations in the rate of the force pulling the pad perpendicularly from the wall, to measure the attachment force of the suction pad under a sudden external load. The load rates were varied by $20 \mathrm{~N} / \mathrm{sec}, 40 \mathrm{~N} / \mathrm{sec}$, and $70 \mathrm{~N} / \mathrm{sec}$, and it could be confirmed that the higher the load rate, the higher the maximum attachment force.

However, the force was lower than $249 \mathrm{~N}$, which was the maximum force under a static load, by about $50 \%$. This means that the suction pad yields a higher attachment force under a static load than under a dynamic load. The results disclosed in this paper could serve as useful data when determining the specifications of suction pads to be used in gondola or robot systems for work on a building's outer walls.
However, further tests should be conducted on a greater variety of suction pads (in terms of their types and shapes) and wall surface configurations.

Further tests will be conducted to investigate the attachment forces on step, rib and embossing-type walls and under a vibrating load.

\section{ACKNOWLEDGEMENTS}

The work presented in this paper was funded by the BMRC (Building-Façade Maintenance Robot Research Center), and supported by the Korea Institute of Construction and Transportation Technology Evaluation and Planning (KICTEP) under the Ministry of Land, Transport and Maritime Affairs(MLTM).

\section{REFERENCES}

[1] Guido La Rosa, Michele Messina, Giovanni Muscato, R. Sinatra, "A low-cost lightweight climbing robot for the inspection of vertical surfaces", Mechatronics, Vol 12, pp. 71-96, 2002.

[2] Nishi A., "A biped walking robot capable of moving on a vertical wall”, Mechatronics, Vol. 2 (6), pp. 543-554, 1992.

[3] Nishi A., "Development of wall-climbing robots", Compute Electron Eng, Vol. 22(2), pp. 123-149, 1996.

[4] Nishi A., Miyagi H., "A wall climbing robot using the thrust force of a propeller mechanism and control in a strong wind", JSME Int J Ser C, Vo1. 37, pp. 172-178, 1994.

[5] Hwang Kim, Dongmok Kim, Hojoon Yang, Kyouhee Lee, Kunchan Seo, Doyoung Chang, Jongwon Kim, "A wall climbing robot with a vacuum caterpillar wheel system operated by a mechanical valve", Proceedings of the 9th International Conference on Climbing and Walking Robots, pp. 28-33, 2006. 